\title{
Interactive association of maternal education and peer relationship with oppositional defiant disorder: an observational study
}

\author{
Ming-Chia Liu', Jung Chen Chang ${ }^{2,3}$ and Chau-Shoun Lee ${ }^{1,4^{*}}$
}

\begin{abstract}
Background: The objectives of this research were to gain insights on the interactive effects, by measuring familial and peer-related risk factors in youths with oppositional defiant disorder (ODD).

Methods: Participants were college students recruited nationwide, with age between 18 and 25. Through the consensus of expert meetings, a set of questionnaires were used to evaluate the familial status, participant's peer group conditions, high-risk environment of illicit substance use, and oppositional symptoms. The logistic regression was performed to see the independent and interactive risk factors for ODD.

Results: A total of 981 subjects were enrolled. Six variables significantly associated with ODD at the multivariate logistic regression, including male, night division, poor academic performance, high risk environment, peer with illicit substance use and high maternal education level. High maternal education exerted independent protective effect on the development of ODD (adjusted odds ratio, aOR $=0.65,95 \% \mathrm{Cl}=0.44-0.99$ ). Peer with illicit substance use was more likely to associate with ODD in the low maternal education group. The 2-way interactive effect of maternal education and peer with substance use on the development of ODD was OR $=4.96(2.96,8.31)$.

Conclusion: The present study highlights the influence of maternal education level to ODD and its interaction with peer of illicit substance use. Our findings imply that the familial attachment and peer interaction are essential stages for the development of human behavior.
\end{abstract}

Trial registration: The research protocol was reviewed and approved by the ethical review committee of National Taiwan University Hospital (number 201505057RINC) and registered at clinical trial systems at National Taiwan University. In addition, subjects' information was anonymous and de-identified prior to any analysis.

Keywords: Oppositional defiant disorder, Mother-child relations, Peer interaction, Illicit substance use

\footnotetext{
* Correspondence: csleepsyc@gmail.com

'Department of Psychiatry, MacKay Memorial Hospital, Taipei, Taiwan

${ }^{4}$ Department of Medicine, MacKay Medical College, New Taipei City, Taiwan

Full list of author information is available at the end of the article
}

(C) The Author(s). 2021 Open Access This article is licensed under a Creative Commons Attribution 4.0 International License, which permits use, sharing, adaptation, distribution and reproduction in any medium or format, as long as you give appropriate credit to the original author(s) and the source, provide a link to the Creative Commons licence, and indicate if changes were made. The images or other third party material in this article are included in the article's Creative Commons licence, unless indicated otherwise in a credit line to the material. If material is not included in the article's Creative Commons licence and your intended use is not permitted by statutory regulation or exceeds the permitted use, you will need to obtain permission directly from the copyright holder. To view a copy of this licence, visit http://creativecommons.org/licenses/by/4.0/ The Creative Commons Public Domain Dedication waiver (http://creativecommons.org/publicdomain/zero/1.0/) applies to the data made available in this article, unless otherwise stated in a credit line to the data. 


\section{Background}

About one in five children and youths met criteria for a mental disorder but less than one-third had received a mental health professional service in a Canadian study [1]. To strengthen prevention and early intervention efforts by depicting familial and peer influences are essential to meet the mental health needs of youths. Of the mental disorders in youths, oppositional defiant disorder (ODD) represents enduring patterns of argumentative, disobedient attitude toward authority figures, characterized with irritable mood and vindictiveness. ODD is one of the most commonly encountered clinical disorders in children and adolescents. The clinician is most often alerted when problems with oppositionality, vindictiveness, negativistic and hostile behavior which create a significant disturbance in social, academic, or occupational functioning [2]. Data from Avon Longitudinal Study of Parents and Children have shown individuals with ODD were likely to develop anxiety, depression or conduct disorder in the long term follow-up [3]. The Cambridge study on delinquency also found that ODD persons had higher rate of hospitalization or being registered disabled in their middle age [4]. As ODD is among the most common reasons referred to mental health professionals, primary care physicians are positioned to assess youth at risk of ODD and refer their families to community programs [5].

Both familial and peer factors had been found to associate with the ODD. Familial factors, such as parent emotional regulation and cohesion, are related to child ODD symptoms and understanding child behavioral problems within the family context is important [6]. Harsh inconsistent discipline, low warmth and involvement, and high criticism parenting styles were considered risky for the ODD [7]. The parenting style might correlate with children's externalizing behaviors [8]. Parents' own antisocial behavior also played a role on the development of children's oppositional problems [9]. During childhood and adolescence, the oppositional child may be rejected by non-deviant peers and tends to attract other deviant ones. The affiliation with deviant peers were more likely to reinforce mutual antisocial behaviors [10]. The poor social skills and lack of prosocial behaviors were common among children with ODD [11]. These familial and peer factors were found to influence children's defiance through parenting practices and social skill learning at peer interactions. Also, social learning theories have shown that individual who witnesses more deviant behaviors from their parents or peers would model the advantage of these behaviors, thus promoting aggression and oppositional behaviors [12].

Although various familial and peer factors were explored for their impact on ODD, the interactive effects were seldom examined. In the present study, we planned to figure out the independent and interactive relationship of these 2 types of risk factors with the ODD. Our hypothesis was that high educated parents may be a protective factor toward the development of ODD. And deviant peer group, such as those with substance use or going to risky environment, may increase the risk of developing $O D D$. The sample was coming from a national project of Screening for Illicit Substance Use in College (SISUC).

\section{Methods}

\section{Study design}

This study used data from a campus prevention program, the SISUC, which involved about $80 \%$ of 151 colleges and universities nationwide [13]. At the first stage, we sent an invitation letter to school personnel in the office of Student Affairs and consecutively recruited schools into the SISUC study. A cross-sectional survey with non-randomized sampling in 14 universities were recruited to join the early phase of the SISUC study. The above 14 universities located in different regions of Taiwan and were public or private supported, and either general- or vocational-oriented. A set of self-report questionnaires were administered to identify the highrisk population and risk factors for illicit substance use. (supplement 1) The measures were given to classes of students and the participants, who understood the purpose and value of the research, might hand in completed questionnaires under anonymity. The main reasons of non-participation were time-limit or not interested and the averaged acceptance rate was $75 \%$ among invited students.

\section{Study participants}

Study participants were college or university students recruited across northern, central and southern Taiwan in 2014, with age between 18 and 25. We contacted school nurses, psychologists, teachers, mentors, or counselors and invited the students to participate in the program through those staff once they meet the inclusion and exclusion criteria. The inclusion criteria included:1) being Taiwanese citizen, 2) aged 18 to 25,3) currently studying in day or night division of the college or university, 4) with no diagnosed developmental delay that may compromise their understanding of study purpose. The exclusion criteria include:1) participants with severe mental illnesses, 2) physical disabilities, or 3) cognitive impairment. Each participant was given a written instruction to inform the study related information before participation. The researchers or research assistants explained the purpose and procedure of the program to the participants in classrooms and collected the questionnaire directly under their consents. The original estimated size of sample was at least 906 based on logistic regression with odds ratio 1.45, alpha error probability 0.05, having $80 \%$ 
power, and $10-20 \%$ attrition rate. The response rate was $75 \%$. They were told that the data of questionnaires would be kept confidential and have no impact to their academic evaluation.

\section{Study measures}

\section{Demographic characteristics}

The demographic information collected was age, sex, day or night division of school, academic performance, personal income, family type, family income, and parental working status and educational level. Poor academic performance meant failure in more than half of their curricula in a semester. Personal income was divided into three levels: no income, moderate income (below 12,000 Taiwan dollars (TWD) per month) and high income (over 12,000 TWD per month). The single-parent and two-parent family types were also reported. Family economic status was categorized as affluence, balanced, and liabilities. Parental working status were analyzed separately as unemployed or employed father and unemployed or employed mother. Paternal and maternal educational levels were recorded as low and high levels ( $\leqq 9$ years and $>9$ years).

\section{The youth risk behavior surveillance system (YRBSS)}

The open website YRBSS was modified and used to survey 6 categories of health or risk behaviors in youth and young adults, including behaviors that contribute to unintentional injuries and violence. This system updates every 2 years with satisfactory reliability $[14,15]$.

\section{The semi-structured assessment for drug dependence and alcoholism (SSADDA)}

SSADDA was designed according to DSM-IV [16] for assessment of drug and alcohol abuse. It also evaluated the individual's oppositional behaviors and relevant environmental problems. SSADDA had good inter-rater reliability [17].

\section{The Chinese version of the schedule for affective disorders and schizophrenia for school-age children- epidemiologic version (K-SADS-E)}

K-SADS-E was a semi-structure diagnostic interview scale, developed for assessing youth mental disorders [18]. It has been translated into several languages and used worldwide. The Chinese version has been tested and showed good inter-rater reliability and convergent and divergent validity with other corresponding clinical questionnaires [19].

The relevant items from above measures were integrated into a set of questionnaires through the consensus of expert meetings. This set of questionnaires was used to evaluate the participant's peer group conditions, personal history, and high-risk environment of illicit substance use, and to screen behavior problems such as oppositional and conduct disorders.

\section{Assessment of oppositional disorder}

We selected 8 questions out of Chinese K-SADS-E according to DSM-5 criteria to detect ODD [20]. The items included "loses temper", "argue with adult/authority figures", "disobey rules or requests", "deliberately annoying others", "blame others for own mistakes", "touchy and easily annoyed", "resentful", and "vindictiveness". The participant meeting more than 4 criteria was considered as a possible case.

\section{Statistical analyses}

Statistical analysis was conducted using R v3.5.0 ( $\mathrm{R}$ core team, 2014). The univariate regression analysis was performed to find the correlation between each risk factor, such as demographic or clinical characteristics, and ODD. The multivariate regression was then carried out to estimate the independent and interactive effects of co-variates on the ODD. The potential confounders in this study included demographic backgrounds (i.e., age, sex, economic status, family type, parental employment), schooling factors (i.e., day or night division, academic performance), peer influences (peer with conduct behaviors), and environmental factors, such as high risk environment for illicit substance abuse. All those potential confounders were considered in the statistical analyses. We performed a post-hoc analysis by stratification of maternal education level. The crude odd ratio (OR), adjusted OR and 95\% confidence interval were calculated and the $p<0.05$ was considered as the significant level. There were few missing data $(<1 \%)$ for each variable because of the nature of voluntary participation with careful preparation and clear explanation beforehand as well as friendly reminding to check for blanks by research assistants during the process. We used missing value imputation to address missing data for statistics, such as using the same school averaged income level for missing income. A questionnaire could be valid only if the missing items were less than $20 \%$ of the entire questionnaire booklet. As we intended to understand the association of familial attachment and peer interaction with the case of ODD, a post-hoc analyses were performed on the relevant variables.

\section{Results}

A total of 981 subjects between 18 and 25 years of age were enrolled from 14 schools. Social demographic characteristics associated with ODD are shown in Table 1. In the univariate analyses, male $(\mathrm{OR}=2.43)$, study in night division providing classes in the evening $(\mathrm{OR}=2.12)$, living in a single-parent family $(\mathrm{OR}=1.75)$, poor academic performance $(\mathrm{OR}=1.95)$, high personal income $(\mathrm{OR}=2.25)$, going to high risk environment of illicit substance use $(\mathrm{OR}=$ $5.61)$, and peer with conduct behavior $(\mathrm{OR}=1.77$,) or illicit substance use $(\mathrm{OR}=2.78)$ were significantly correlated with the possible case of ODD. Comparing to the low 
Table 1 Sociodemographic data associated with oppositional defiant disorder in the univariate and multivariate logistic regressions $(n=981)$

\begin{tabular}{|c|c|c|c|c|c|}
\hline Variables & n (\%) & Crude OR $(95 \% \mathrm{Cl})$ & $p$-Value & Adjusted OR (95\% Cl) & p-Value \\
\hline Age Range (y) & $18-25$ & & & & \\
\hline \multicolumn{6}{|l|}{ Sex } \\
\hline Female & $534(54.43)$ & 1 & & & \\
\hline Male & $447(45.56)$ & $2.43(1.72,3.45)$ & $<0.001$ & $1.94(1.34,2.83)$ & 0.001 \\
\hline \multicolumn{6}{|l|}{ Division Of College } \\
\hline Day Division & $488(49.74)$ & 1 & & & \\
\hline Night Division ${ }^{\mathrm{a}}$ & $493(50.25)$ & $2.12(1.50,3.02)$ & $<0.001$ & $1.74(1.19,2.56)$ & 0.005 \\
\hline Family Type & & & 0.002 & & \\
\hline Double-Parent & $256(26.09)$ & 1 & & & \\
\hline Single-Parent & $725(73.91)$ & $1.75(1.22,2.49)$ & & & \\
\hline Father Working Status & & & 0.29 & & \\
\hline Unemployed & $65(6.63)$ & 1 & & & \\
\hline Employed & $916(93.37)$ & $1.39(0.73,2.5)$ & & & \\
\hline Father Education Level & & & 0.74 & & \\
\hline Low Education & $266(27.11)$ & 1 & & & \\
\hline High Education & 715 (72.88) & $0.94(0.65,1.37)$ & & & \\
\hline Mother Working Status & & & 0.567 & & \\
\hline Unemployed & $336(34.25)$ & 1 & & & \\
\hline Employed & $645(65.74)$ & $0.90(0.63,1.28)$ & & & \\
\hline Mother Education Level & & & 0.016 & & 0.042 \\
\hline Low Education ${ }^{d}$ & $229(23.34)$ & 1 & & 1 & \\
\hline High Education & 752 (76.66) & $0.64(0.44,0.93)$ & & $0.65(0.44,0.99)$ & \\
\hline Poor Academic Performance ${ }^{c}$ & $138(14.06)$ & $1.95(1.27,2.96)$ & 0.002 & $1.86(1.15,2.98)$ & 0.011 \\
\hline Peer with Conduct Behavior & $397(40.46)$ & $1.77(1.26,2.48)$ & 0.001 & & \\
\hline Peer With Illicit Substance Use & $374(38.12)$ & $2.78(1.98,3.92)$ & $<0.001$ & $2.11(1.45,3.07)$ & 0.0001 \\
\hline High Risk Environment of Illicit Substance Use & $410(41.79)$ & $5.61(3.86,8.29)$ & $<0.001$ & $5.64(3.83,8.45)$ & $<0.0001$ \\
\hline \multicolumn{6}{|l|}{ Personal Income $e^{b}$} \\
\hline No Income & 309 (31.49) & 1 & $<0.001$ & & \\
\hline Moderate Income & $252(25.68)$ & $1.06(0.66,1.67)$ & 0.813 & & \\
\hline High Income & $420(42.81)$ & $2.25(1.54,3.32)$ & $<0.001$ & & \\
\hline \multicolumn{6}{|l|}{ Family economic status } \\
\hline Affluence & $264(26.91)$ & 1 & $<0.001$ & & \\
\hline Balanced & $529(53.92)$ & $0.62(0.37,1.04)$ & 0.717 & & \\
\hline Liabilities & $188(19.16)$ & $0.92(0.61,1.43)$ & 0.071 & & \\
\hline
\end{tabular}

$O R$ odds ratio; $\mathrm{Cl}$ confidence interval; crude OR for the univariate regression and adjusted OR for the multivariate regression

${ }^{a}$ A division providing evening classes for those working during the daytime

${ }^{b}$ Moderate income, below 12,000 Taiwan dollars (about 400 USD) per month; high income, over 12,000 Taiwan dollars per month

'Poor academic performance meant failure in more than half of their curricula in a semester

${ }^{d}$ Educational level: low $\leq 9$ years and high $>9$ years

Numbers of missing data for each variable were as below: 85 for age, 2 for sex, 5 for division, peer with conduct behavior, peer using illicit substance, and high

risk environment, 6 for family type, 68 for father's work, 93 for father's education, 28 for mother's work, 76 for mother's education, 13 for poor academic

performance, 77 for personal income, and 63 for family economic status

educational level, higher maternal education was less likely to develop ODD $(\mathrm{OR}=0.64)$.

Table 1 also shows the adjusted odds ratio of demographic, familial and peer factors on the risk of ODD.
Six variables remained significant at the multivariate logistic regression, including male, night division, poor academic performance, high risk environment, peer with illicit substance use and high maternal education level. 
High maternal education persisted to exert independent protective effect on the development of ODD $(\mathrm{aOR}=0.65)$.

At a further inspection, we stratified the familial factor, maternal educational level, to analyze the differential impact of peer factors on the ODD. In the Table 2, two factors exerted distinct impact on the presence of ODD. Peer with illicit substance use was more likely to associate with ODD in the low maternal education group, but study in the night division made the significant effect in the high level counterpart. We in particular calculated the 2-way interactive effect of maternal education and peer with illicit substance use on the development of ODD, and O.R. $=4.96(2.96,8.31)$ was found.

\section{Discussion}

Our study investigated the associated risk factors for ODD and 6 factors were found to exert independent association, including gender, campus problems, peer interaction and familial variables. We specifically inspected the interactive impact of peer and familial factors on the presence of ODD. The high maternal education level provided a significant protective effect on the male college student at facing the substance enabler in peers.

The current study showed young adult male (age 1825) was more likely to have ODD than female, which is consistent with previous epidemiology surveys. The gender is constantly a significant predictor for oppositional and further antisocial behavior [21]. However, the prevalence rate of ODD in boys outnumber girls before adolescent, the male predominance existing but declining among adolescent and adult samples. This sex difference of ODD is possibly affected by sociocultural factors, apparent in Western society but not so significant for nonWestern culture [22].

As to the influencing factors in family, it is suggested that highly educated mother may use the more sensitive parenting style instead of controlling way [23, 24]. These mothers are likely to know about the importance of keeping consistent and warm parenting style, which thus reduces the externalizing problems in youths [7, 25]. Moreover, the better maternal working memory or cognitive control of emotion along with decreased harsh reactive parenting was found to lessen the oppositional reactivity at interaction with children [26]. Our finding that mother with higher educational level was a protective factor for the development of ODD is compatible with those findings.

In contrast, low educated mothers were more neglectful and this parenting style itself increased the risk of developing ODD in children [27]. Our survey showed that the concurrence of low maternal education level and peer with illicit substance use exerted the highest risk for having the ODD. It is possible that the low educated mother uses dysfunctional parenting style and is less likely to monitor her child's peer relationship and whereabouts. As the child, particularly boy, had delinquent peers around, he was at risk to increase delinquent behavior and developing oppositional behavior. The illicit substance use in adolescents may predict future conduct problems [28]. Youths with deviant peers would increase their rates of antisocial behaviors after joining a gang, which risk reduces if leaving the gang [29]. The maternal support had not only direct effect on reducing the delinquency but also acting indirectly on deviant peer affiliation [30].

The exposure to high risk environment of illicit substance use persisted highly associated with the ODD despite the protective effect of high maternal education level. A student studying in the night division was more likely to have ODD when mother well educated than with a low educated mother. Studying in night division might be the result of low academic achievement at senior high school or during university entrance exam, particularly for students in higher socioeconomic family. The previous study has showed that the low IQ and low school achievement are important predictors of ODD [31]. Students with low performance may encounter unrewarding experiences through the school lives and turn out to seek support from deviant peers. As deviant youths get together, they possibly reinforce mutual

Table 2 Adjusted odds ratio of demographic and peer risk factors for the ODD stratified by maternal education level

\begin{tabular}{|c|c|c|c|c|}
\hline & \multicolumn{2}{|c|}{ High Maternal Education } & \multicolumn{2}{|c|}{ Low Maternal Education } \\
\hline & aOR $(95 \% \mathrm{Cl})$ & $p$ & aOR $(95 \% \mathrm{Cl})$ & $p$ \\
\hline High-Risk Environment* & $5.55(3.20,10.01)$ & $<0.001$ & $5.11(2.45,11.28)$ & $<0.001$ \\
\hline Peer with illicit Substance Use & $1.72(1.01,2.93)$ & 0.045 & $2.82(1.35,6.00)$ & 0.01 \\
\hline Male & $1.75(1.03,2.99)$ & 0.039 & $2.96(1.42,6.41)$ & 0.01 \\
\hline Poor Academic Performance & $1.78(0.89,3.47)$ & 0.096 & $1.87(0.72,4.73)$ & 0.19 \\
\hline Night Division & $2.67(1.55,4.71)$ & $<0.001$ & $0.95(0.46,1.99)$ & 0.90 \\
\hline
\end{tabular}

Note: The 2-way interaction, mother with low education level x peer with illicit substance use, was calculated: Odds Ratio $(95 \% \mathrm{Cl})=4.96(2.96,8.31)$,

p-value $<0.0001$

aOR $=$ adjusted odds ratio;

*high-risk environment meant high risk environment of illicit substance abuse 
delinquent behaviors [10]. The interaction also increases the risk of developing ODD. At another direction, ODD is commonly a disorder of childhood. Its symptoms significantly interfere with social or interpersonal relationships at primary and middle schools. The persistence of impairment associated with ODD into young adulthood may make the patient enter a night division of college despite the socioeconomic advantage. This phenomenon also calls for a reconsideration of ODD as a disorder limited to childhood [32].

Despite those intriguing findings, our survey is limited by its cross-sectional design and temporal relationship among risk factors and ODD cannot be well defined. Therefore, we could not confirm the causal direction of risk factors and the disorder. Secondly, the definition of ODD is according to the self -administered questionnaire instead of interview, thus not a formal diagnosis. Though the questionnaire is made from diagnostic criteria, potential bias might come from the different interpretation of the symptom questions between participants and experts. However, the present assessment of ODD symptoms offered the advantage of variability in a nonclinical sample. Moreover, the sample was all from college students, not the community population. The selection bias exists and generalizability is restricted. We made every possible effort to address the potential sources of bias. First, we recruited participants from both general and vocational colleges and universities, from both public and private schools, from urban and rural areas, from day and night divisions, and from more than half counties nationwide. Second, we provide leaflets, invitation letter, and oral explanation to increase the understanding of self-report questionnaire for participants. We also address that all the answers were processed anonymously and aimed for medical or educational concern not for any legal concern or persecution purpose to increase the truthfulness of the self-reports. Third, we handled the data carefully and rechecked with expert penal from time to time to verify the findings comparable to clinical impressions and campus real world conditions. Forth, we used multivariate regression and calculate the receiver operating characteristic curve (ROC curve) to see the sensitivity and specificity of our model. The interaction ROC curve were 0.79, indicating the acceptable discrimination of our model.

\section{Conclusions}

This study found that family and peer factors interacted to exert the highest effect for developing ODD. It gives implications of importance at developing relevant programs to prevent college students from poor long-term outcome. In addition to enhance supportive parenting skills, positive campus experiences might help the student resisting the risky peer influence [33, 34]. The concern of the generalizability (external validity) is a construct that attempts to answer whether we can use the results of the current study in college students other than those enrolled in the study. The participants' profiles, such as demographics and social-economic status (SES), were similar to general college students in Taiwan. However, it needs cautions to penalize the findings to other counties with significantly non-comparable SES or without similar healthcare and educational resources. In order to increase the generalizability, further study may need more rigorous design, such as collect data from the general population, enroll ethnical minorities, conduct an international collaborative study, perform longitudinal trend analysis to increase the external validity.

\section{Abbreviations}

ODD: Oppositional defiant disorder; SISUC: Screening for Illicit Substance Use in College; TWD: Taiwan dollars; YRBSS: The Youth Risk Behavior Surveillance System; SSADDA: The Semi-Structured Assessment for Drug Dependence and Alcoholism; K-SADS-E: The Chinese version of the Schedule for Affective Disorders and Schizophrenia for School-Age Children-Epidemiologic Version; OR: Odd ratio; aOR: Adjusted OR; IQ: Intelligence quotient; ROC

curve: Receiver operating characteristic curve; SES: Social-economic status

\section{Supplementary Information}

The online version contains supplementary material available at https://doi. org/10.1186/s12888-021-03157-7.

\section{Additional file 1}

\section{Acknowledgements}

All authors would like to give our great Thanks to the health care provider and the research associates for their contribution to this work.

\section{Authors' contributions}

JC contributed in conceptualize and administrate the study, funding acquisition, and complete data collection. All authors participated in analyzed and interpreted the data. ML wrote the original draft of the manuscript, $J C$ and $C L$ reviewed and edited the final version. All authors read and approved the final manuscript.

\section{Funding}

The SISUC project led by Associate professor Jung-Chen Chang was funded by the Ministry of Education (MOE), Executive Yuan, Taiwan [Grant numbers:103A142]. The MOE had no role in the design, the collection, analysis, and interpretation of data, the writing of the report, and to submit the paper for publication.

\section{Availability of data and materials}

Data are available upon reasonable request, subject to the required approvals. All data were obtained by individual self-reported questionnaire. Access to the statistical code and the dataset can be requested from the corresponding author at jungchenchang@ntu.edu.tw. Requests will be granted after consideration by the SISUC Research Group, agreement by the National Taiwan University Hospital Research Ethics Committee.

\section{Declarations}

Ethics approval and consent to participate

There were no patients or the public involved in the design, or conduct, or reporting, or dissemination plans of our research. All procedures involved in this work comply with the ethical standards of the relevant national and institutional committees on human experimentation and with the 1975 Helsinki Declaration, revised in 2008. The research protocol was reviewed and approved by the ethical review committee of National Taiwan University 
Hospital (number 201505057RINC). Informed consent was obtained from all participants. In addition, subjects' information was anonymous and deidentified prior to any analysis.

\section{Consent for publication}

Not applicable.

\section{Competing interests}

No authors have financial or nonfinancial competing interests in the publication of this paper.

\section{Author details}

${ }^{1}$ Department of Psychiatry, MacKay Memorial Hospital, Taipei, Taiwan. ${ }^{2}$ School of Nursing, College of Medicine, National Taiwan University, Taipei, Taiwan. ${ }^{3}$ Department of Nursing, National Taiwan University Hospital, Taipei, Taiwan. ${ }^{4}$ Department of Medicine, MacKay Medical College, New Taipei City, Taiwan.

Received: 25 October 2020 Accepted: 4 March 2021

Published online: 22 March 2021

\section{References}

1. Georgiades K, Duncan L, Wang L, Comeau J, Boyle MH. Ontario child health study T: six-month prevalence of mental disorders and service contacts among children and youth in Ontario: evidence from the 2014 Ontario child health study. Can J Psychiatr. 2019;64(4):246-55. https://doi.org/10.11 77/0706743719830024.

2. Steiner $H$, Remsing $L$. Work group on quality l: practice parameter for the assessment and treatment of children and adolescents with oppositional defiant disorder. J Am Acad Child Adolesc Psychiatry. 2007;46(1):126-41. https://doi.org/10.1097/01.chi.0000246060.62706.af.

3. Whelan YM, Stringaris A, Maughan B, Barker ED. Developmental continuity of oppositional defiant disorder subdimensions at ages 8, 10, and 13 years and their distinct psychiatric outcomes at age 16 years. J Am Acad Child Adolesc Psychiatry. 2013;52(9):961-9. https://doi.org/10.1 016/j.jaac.2013.06.013.

4. Piquero AR, Shepherd I, Shepherd JP, Farrington DP. Impact of offending trajectories on health: disability, hospitalisation and death in middle-aged men in the Cambridge study in delinquent development. Crim Behav Ment Health. 2011;21(3):189-201. https://doi.org/10.1002/cbm.810.

5. Riley M, Ahmed S, Locke A. Common questions about oppositional defiant disorder. Am Fam Physician. 2016;93(7):586-91.

6. Lin X, Li L, Heath MA, Chi P, Xu S, Fang X. Multiple levels of family factors and oppositional defiant disorder symptoms among Chinese children. Fam Process. 2018;57(1):195-210. https://doi.org/10.1111/famp.12269.

7. Michael Rutter HGAH. Antisocial behaviour by young people. Cambridge: Cambridge University Press; 1998.

8. Stanger C, Dumenci L, Kamon J, Burstein M. Parenting and children's externalizing problems in substance-abusing families. J Clin Child Adolesc Psychol. 2004;33(3):590-600. https://doi.org/10.1207/s15374424jccp3303_16.

9. Frick PJ, Lahey BB, Loeber R, Stouthamer-Loeber M, Christ MA, Hanson K. Familial risk factors to oppositional defiant disorder and conduct disorder: parental psychopathology and maternal parenting. J Consult Clin Psychol. 1992;60(1):49-55. https://doi.org/10.1037/0022-006X.60.1.49.

10. Boivin M, Brendgen M, Vitaro F, Forget-Dubois N, Feng B, Tremblay RE, Dionne G. Evidence of gene-environment correlation for peer difficulties: disruptive behaviors predict early peer relation difficulties in school through genetic effects. Dev Psychopathol. 2013;25(1):79-92. https://doi.org/10.1017/ S0954579412000910.

11. Paap MC, Haraldsen IR, Breivik K, Butcher PR, Hellem FM, Stormark KM. The link between peer relations, Prosocial behavior, and ODD/ADHD symptoms in 7-9-year-old children. Psychiatry J. 2013;2013:319874.

12. Roubinov DS, Boyce WT, Bush NR. Informant-specific reports of peer and teacher relationships buffer the effects of harsh parenting on children's oppositional defiant disorder during kindergarten. Dev Psychopathol. 2020; 32(1):163-74. https://doi.org/10.1017/S0954579418001499.

13. Yi-Ting Chen J-CC, Lee C-S. Screening illicit substance use in college students: the Chinese version of the drug abuse screening test. Drug Alcohol Depend. 2020;215:10814.
14. Raghupathy S, Hahn-Smith S. Reliability of the high school youth risk behavior survey when administered online. Int Q Community Health Educ. 2011;32(2):135-48. https://doi.org/10.2190/IQ.32.2.d.

15. Kann L, McManus T, Harris WA, Shanklin SL, Flint KH, Hawkins J, Queen B, Lowry R, Olsen EO, Chyen D, et al. Youth risk behavior surveillance - United States, 2015. MMWR Surveill Summ. 2016;65(6):1-174.

16. American Psychiatric Association A. Diagnostic and statistical manual of mental disorders. 4th ed. Washington DC: American Psychiatric Association; 1994.

17. Denis CM, Gelernter J, Hart AB, Kranzler HR. Inter-observer reliability of DSM5 substance use disorders. Drug Alcohol Depend. 2015;153:229-35. https:// doi.org/10.1016/j.drugalcdep.2015.05.019.

18. Orvaschel H: Schizophrenia and affective disorders schedule for children-epidemiological version (KSADS-E). University N. Unpbulished manuscript; 1995.

19. Chen YL, Shen LJ, Gau SS. The mandarin version of the kiddie-schedule for affective disorders and schizophrenia-epidemiological version for DSM-5 - a psychometric study. J Formos Med Assoc. 2017;116(9):671-8. https://doi. org/10.1016/j.jfma.2017.06.013.

20. American Psychiatric Association A. Diagnostic and statistical manual of mental disorders (DSM-5 ${ }^{\oplus}$ ). 5th ed. Washington, DC: American Psychiatric Association; 2013. https://doi.org/10.1176/appi.books.9780890425596.

21. Odgers CL, Moffitt TE, Broadbent JM, Dickson N, Hancox RJ, Harrington H, Poulton R, Sears MR, Thomson WM, Caspi A. Female and male antisocial trajectories: from childhood origins to adult outcomes. Dev Psychopathol. 2008;20(2):673-716. https://doi.org/10.1017/S0954579408000333.

22. Demmer DH, Hooley M, Sheen J, McGillivray JA, Lum JA. Sex differences in the prevalence of oppositional defiant disorder during middle childhood: a meta-analysis. J Abnorm Child Psychol. 2017:45(2):313-25. https://doi.org/1 0.1007/s10802-016-0170-8

23. Dornbusch SM, Ritter PL, Leiderman PH, Roberts DF, Fraleigh MJ. The relation of parenting style to adolescent school performance. Child Dev. 1987;58(5):1244-57. https://doi.org/10.2307/1130618.

24. Tamis-Lemonda CS, Briggs RD, McClowry SG, Snow DL. Maternal control and sensitivity, child gender, and maternal education in relation to Children's behavioral outcomes in African American families. J Appl Dev Psychol. 2009;30(3):321-31. https://doi.org/10.1016/j.appdev.2008.12.018.

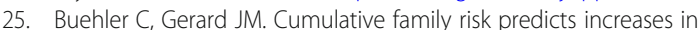
adjustment difficulties across early adolescence. J Youth Adolesc. 2013;42(6): 905-20. https://doi.org/10.1007/s10964-012-9806-3.

26. Deater-Deckard K, Sewell MD, Petrill SA, Thompson LA. Maternal working memory and reactive negativity in parenting. Psychol Sci. 2010;21(1):75-9. https://doi.org/10.1177/0956797609354073.

27. Van der Geest KE, Merelle SYM, Rodenburg G, Van de Mheen D, Renders CM. Cross-sectional associations between maternal parenting styles, physical activity and screen sedentary time in children. BMC Public Health. 2017; 17(1):753. https://doi.org/10.1186/s12889-017-4784-8.

28. Wymbs BT, McCarty CA, Mason WA, King KM, Baer JS, Vander Stoep A, McCauley E. Early adolescent substance use as a risk factor for developing conduct disorder and depression symptoms. J Stud Alcohol Drugs. 2014; 75(2):279-89. https://doi.org/10.15288/jsad.2014.75.279.

29. Murray J, Farrington DP. Risk factors for conduct disorder and delinquency: key findings from longitudinal studies. Can J Psychiatr. 2010;55(10):633-42. https://doi.org/10.1177/070674371005501003.

30. Deutsch AR, Crockett LJ, Wolff JM, Russell ST. Parent and peer pathways to adolescent delinquency: variations by ethnicity and neighborhood context. J Youth Adolesc. 2012;41(8):1078-94. https://doi.org/10.1007/s10964-012-9754-y.

31. Goodman R, Simonoff E, Stevenson J. The impact of child IQ, parent IQ and sibling IQ on child behavioural deviance scores. J Child Psychol Psychiatry. 1995:36(3):409-25. https://doi.org/10.1111/j.1469-7610.1995.tb01299.x.

32. Burke JD, Rowe R, Boylan K. Functional outcomes of child and adolescent oppositional defiant disorder symptoms in young adult men. J Child Psychol Psychiatry. 2014;55(3):264-72. https://doi.org/10.1111/jcpp.12150.

33. Dishion TJ, McCord J, Poulin F. When interventions harm. Peer groups and problem behavior. Am Psychol. 1999;54(9):755-64. https://doi.org/10.1037/ 0003-066X.54.9.755.

34. Sweeten G, Piquero AR, Steinberg L. Age and the explanation of crime, revisited. J Youth Adolesc. 2013;42(6):921-38. https://doi.org/10.1007/s10964-013-9926-4.

\section{Publisher's Note}

Springer Nature remains neutral with regard to jurisdictional claims in published maps and institutional affiliations. 